\title{
GLOBALIZACIÓN - MUNDIALIZACIÓN: ¿DOS CARAS DE LA MISMA MONEDA?
}

\author{
Por: Antonio Elizal de Hevia
}

\section{Resumen}

Se aborda en este artículo el problema de la globalización como la síntesis de un proceso al que ha llegado la humanidad, y como un concepto de naturaleza polisémica al cual se aproximan otras ideas como la de "aldea global" de McLuhan, o la de "sistema-mundo" utilizado por el filósofo Wallerstein. Otros conceptos relacionados que se analizan en el artículo, son los de "mundialización", internacionalización, "occidentalización" y "glocalización", Un sexto concepto asociado es el de "planetización", intentando dar cuenta con éste de la crítica a los grandes problemas de nuestro tiempo, en especial el incumplimiento de la promesa de bienestar y los malestares generados por la civilización occidental. Con estos antecedentes se procede a hacer un análisis crítico de las múltiples dinámicas que ha adoptado hoy el fenómeno y de sus consecuencias sobre la vida en el planeta.

\section{Abstract}

This article argues that globalization is a fusion of a process to which humanity has arrived at. Also a natural polysemy concept that other ideas are similar to it, such as McLuhan's

Antonio Elizalde es sociólogo, rector de la Universidad Bolivariana de Chile, presidente del Consejo Editorial de la Revista Polis. Consultor internacional y auto de varios libros y publicaciones en revistas espe"Global Village" or "World-System" used by the philosopher Wallerstein. Other related concepts that have been analyzed in the article are "Universalization", "Internacionalization", "Westernization" and "Global-localization". A sixth related concept is "Planetization" in which one tries to assess the great troubles of our time, specially the unfulfilled promises of welfare and the unrest generated by the western civilization. With these antecedents one can begin to formulate a critical analysis of the various dynamics and life's consequences in the world that the phenomenon has adapted to. 
Introducción: la globalización un proceso que oculta diversas realidades

La palabra "globalización" es una palabra relativamente nueva que, sin embargo, ya forma parte del léxico cotidiano de millones de personas y que dejó atrás hace ya algún tiempo a otras como imperialismo, colonialismo, marxismo, capitalismo, etc. Millones de veces cada día es referida por alguien en el mundo. Muchas de estas veces unida a otra, también muy de moda desde hace algunas décadas: neoliberalismo.

No obstante, esta expansión de su uso, la palabra todavía en la mente de la gente no llega a ser un concepto. Es más, la mayoría de las personas incluso las personas públicas que la utilizan, no son capaces de definir lo que ella significa y sólo cuando llegamos a visualizar lo que su uso implica, nos damos cuenta de que se trata de la síntesis de un proceso al que ha llegado la humanidad.

El concepto de globalización se ha llegado a transformar en una "muletilla" que es usada tanto por sus partidarios como por sus detractores, para referirse a lo que está ocurriendo actualmente en el mundo. Es tal como lo señala Josep F. Mària i Serrano (2001a) una palabra-ídolo que responde en parte a la verdad de un fenómeno y de un proceso; pero es también un arma que esgrimen algunos para mantener o prolongar situaciones injustas. Esta manipulación es precisamente lo que denuncia la afirmación de Robert M. Solow, Premio Nobel de Econo- mía: “¡Ah, sí, la globalización! Es una maravillosa excusa para muchas cosas."

Reconocemos así que la palabra globalización tiene un carácter polisémico. Tras ella se ocultan diversas realidades. Actualmente recibimos permanentemente información mediante la televisión; podemos comunicarnos por correo electrónico con cualquier lugar del mundo; compramos habitualmente productos importados; más de algún pariente o conocido nuestro trabaja en una empresa multinacional; nos enteramos cotidianamente de la violación de los derechos humanos por parte de ciertos gobiernos en algún lugar del planeta; podemos ver "en vivo y en directo" y "en tiempo real" bodas reales, finales mundiales e incluso conflictos bélicos; y realidades como los tratados de libre comercio, la Unión Europea, el Mercosur o el Pacto Andino, están cada vez más presente en nuestras vidas. Todas ellas son realidades relacionadas con la globalización. Paralelamente esta es la excusa o el argumento de algunos pensadores, hombres de negocios 0 políticos para volver a situaciones de capitalismo feroz, ahora que Occidente, y sobre todo Europa, han alcanzado ciertas cuotas de justicia para todos con el Estado de Bienestar. Es por otra parte, en muchos casos, usada por algunos gobiernos (tanto de países ricos como pobres) para ocultar sus errores de política interior o algunas opciones inconfesables. 
Como lo señala Mària i Serrano (2001a):

"También se relacionan con ella cuestiones importantes que podemos plantearnos: ¿Qué consecuencias tendrá Internet en la educación de nuestros hijos? ¿Qué pasará con los idiomas que hablan pocos millones de habitantes ahora que el inglés se impone como vehículo de comunicación internacional? Los asalariados ¿tenemos que aceptar una pérdida de poder adquisitivo o de prestaciones sociales "porque si no la empresa será poco competitiva y tendrá que cerrar"? ¿Cómo tengo que relacionarme con la cada vez mayor cantidad de extranjeros con los cuales me topo al ir al centro o que trabajan en el edificio en construcción de mi calle? ¿Es necesario un Tribunal Internacional que juzgue a los políticos que violan los derechos humanos?."

Milton Santos (2000) en su último libro, publicado poco antes de su muerte, presenta la globalización como fábula, como perversidad y como posibilidad, señalando la necesidad de transitar desde el pensamiento único a la conciencia universal que permita la construcción de una nueva civilización planetaria.

Según Santos, los actores más poderosos de esta nueva etapa de la globalización se reservan los mejores pedazos del territorio global y dejan los restos para los otros. Pero la mayor perversidad en la producción de la globalización actual no reside tanto en la polarización de la riqueza y de la pobreza, ni en la segmentación de los mercados y de las poblaciones sometidas, ni siquiera en la misma destrucción de la naturaleza. La novedad aterradora reside en la tentativa empírica y simbólica de construcción de un único espacio unipolar de dominación. La tiranía del dinero y de la información, producida por la concentración del capital y del poder, tienen hoy una unidad técnica y una convergencia de normas sin precedentes en la historia del capitalismo. El resultado es una profundización de la competitividad, la producción de nuevos totalitarismos, la confusión de los espíritus y el empobrecimiento creciente de las masas, en tanto los Estados se tornan incapaces de regular la vida colectiva. Es una situación insustentable.

El capitalismo actual, sostiene Santos, en su carácter globalmente destructivo acaba además siendo contradictorio, y lleva a la resistencia de segmentos crecientes de la humanidad a partir de sus distintos lugares. Se produce así, una nueva centralidad de lo social que constituye la base para una nueva política. No pudiendo las mayorías oprimidas "consumir el Occidente globalizado" en sus formas puras (financiera, económica y cultural), aumentará la resistencia a la dominación ultraliberal y consumista publicitada por las grandes organizaciones de los medios de comunicación de masas. La alienación tiende a ser substituida por una nueva conciencia, una nueva filosofía moral, que no será la de los valores mercantiles sino la de la solidaridad y la ciudadanía. 
Es fácil constatar que en el interior de las Ciencias Sociales existe un debate abierto entre las diferentes valoraciones del fenómeno de la globalización. Desde aquellos que consideran que la globalización es una tendencia significativa del mundo actual, pasando por aquellos que sólo la consideran un mito, en el sentido de un concepto "vacío" inventado para ocultar intereses inconfesables, cumpliendo por tanto un papel ideológico, en el sentido de falsa conciencia. Es perfectamente posible que ambas visiones contengan parte de la verdad. Como lo he señalado en un trabajo anterior ${ }^{1}$ es posible hacer dos lecturas diametralmente opuestas del mismo fenómeno.

\section{Origen y evolución del concepto a partir de conceptos relacionados}

El concepto de globalización es un constructo relativamente reciente de las ciencias sociales, es posible incluso que no tenga una antigüedad mayor a dos décadas. Sin embargo fue durante la década pasada donde adquirió definitivamente carta de ciudadanía. Para ello debió diferenciarse de varios otros conceptos cercanos e incluso usados en muchos casos como sus sinónimos. Creo necesario por consiguiente establecer las diferencias y similitudes que nos hagan posible esclarecer el sentido que la palabra globalización ha ido adquiriendo a través

\footnotetext{
'Elizalde, Antonio (2002) "Reflexiones en torno a la globalización: crítica y propuesta" en Globalización y Sustentabilidad. Desafíos y alternativas. Programa Chile Sustentable, Santiago.
}

de su progresivo uso en la literatura especializada.

\section{La aldea global}

Un primer concepto que anticipa al de globalización es el de la "aldea global". Hace ya casi medio siglo, Marshall McLuhan, en sus obras Understanding Media (1954) y en The Gutemberg Galaxy (1962), asentó la idea de la "aldea global" y pronosticó un siglo XXI con grandes transformaciones en la vida y en los medios de comunicación, mediante la globalización del mundo y de la sociedad. Esta "aldea global" empezó a ser una realidad con la llegada e implantación de la red Internet, la cual prescinde de los límites políticos y geográficos. McLuhan diría, probablemente, que ahora más que nunca las computadoras están enlazándonos en la aldea global, tanto más cuando se ha convertido más bien en una especie de teatro global. Con un ordenador y un módem, cualquiera puede irrumpir en la escena mundial.

\section{El sistema-mundo}

Un segundo concepto relacionado es el de "sistema-mundo". Esta noción fue creada por Immanuel Wallerstein (1974) y se constituyó en el objeto de estudio de su esfuerzo teórico. Según su creador, la humanidad ha conocido varios sistemas-mundo con capacidad para presentar una visión global coherente. Pero para Wallerstein y sus colegas, la crisis actual de carácter global es consecuencia de 
cambios fundamentales que atraviesa el sistema-mundo capitalista que emergió hace 500 años y que se ha expandido a escala mundial. El sociólogo norteamericano enfatiza dos aspectos en su análisis: en primer lugar, caracteriza la presente coyuntura mundial como una transición fundamental de una forma de organización social a otra. Señala, en segundo lugar, que el resultado de esta transición no puede ser predeterminado y que el futuro está exclusivamente en las manos de todos nosotros. Wallerstein cuestiona, por lo tanto, las convencionales nociones de la modernidad que nos presentan el mundo como un cúmulo de relaciones sociales, ya sea en perfecto equilibrio funcional o en un estado de permanente conflicto con objetivos y resultados conocidos.

En los tres volúmenes de su libro El sistemamundo moderno, Wallerstein nos ofrece una primera aproximación a las claves de su teoría sociológica. Define el sistema-mundo como una estructura con fronteras, grupos y normas que la legitiman y le dan coherencia. Es un mundo lleno de conflictos que se mantiene en un estado de tensión permanente y que funciona como un organismo que experimenta cambios y que saca a relucir sus fuerzas o debilidades según las circunstancias.

Para Wallerstein, lo que caracteriza un sistema social es su ser endógeno. En otras palabras, el sistema social es, en cierta medida, autosuficiente. Así identifica dos tipos de sistema social. Por un lado, el sistema social pequeño, con una economía de subsistencia autónoma y por el otro, el sistema mundo. La diferencia obvia es la de tamaño. También, el sistema mundo se basa sobre una división de trabajo extensa y una diversidad cultural de múltiples expresiones.

Wallerstein agrega que hasta el presente han existido dos tipos de sistemas-mundo. Por un lado, el sistema-mundo imperio que es articulado políticamente por un régimen centralizado que domina la totalidad del territorio sobre el cual se extiende. Por el otro, el sistema-mundo económico que carece de un sistema político centralizador.

Los sistemas-mundo económicos en la era premoderna eran estructuras muy inestables que evolucionaban hacia imperios o se desintegraban. La particularidad del sistemamundo moderno es que ha dado lugar a una economía-mundo cuya duración lleva 500 años. Aun cuando el sistema-mundo económico puede tener centros políticos, éstos no son permanentes ni hegemónicos. Es el caso de las ciudades del norte de Italia, después Amsterdam (Holanda), Londres (Gran Bretaña) y Nueva York (EEUU), que se han sucedido como capitales del sistema-mundo económico del capitalismo en el último medio milenio. Arrighi y Silver (2001) anuncian un desplazamiento del centro hegemónico actual a corto plazo.

“La globalización del moderno sistemamundo se ha producido pues, mediante una serie de rupturas en los modelos establecidos 
de gobierno, acumulación y cohesión social, en el curso de los cuales el orden hegemónico establecido entraba en decadencia, mientras en sus intersticios emergía un nuevo orden que con el tiempo se convertía en hegemónico... La expansión financiera global de los aproximadamente últimos veinte años no constituye una nueva fase del capitalismo mundial ni anuncia una "incipiente hegemonía de los mercados globales". Por el contrario, indica claramente que nos hallamos inmersos en una crisis de hegemonía. Como tal, cabe esperar que esa expansión no sea sino un fenómeno temporal que acabará más o menos catastróficamente dependiendo de cómo gestione la crisis la potencia hegemónica en declive." (pp. 275-276)

Según Wallerstein, esta falta de centro hegemónico es el secreto de la fuerza del sistemamundo moderno y, a la vez, constituye el lado político de la organización económica llamada capitalismo. El éxito del capitalismo descansaría precisamente sobre esta multiplicidad de sistemas políticos que conviven simultáneamente.

\section{La mundialización}

Un tercer concepto muy relacionado al de globalización es el de "mundialización", incluso usado casi como un sinónimo. Hay una primera versión que se corresponde con la teoría del imperialismo, elaborada en las primeras décadas del siglo por Lenin, Luxemburgo, Bujarín y Trotsky. Como lo señala Claudio Katz ${ }^{2}$ :
"Este análisis apuntó a interpretar el significado de la gran transformación operada con la sustitución del capitalismo librecambista por el monopólico. Este cambio se fundaba, a su vez, en un importante avance de la internacionalización de la economía, especialmente en el plano comercial y financiero, así como en el desarrollo de las primeras formas de inversión directa. Los cuatro teóricos postularon una caracterización convergente del fenómeno, pero resaltaron aspectos diferentes (y controvertidos entre sí) de la nueva etapa.

Mientras que para Lenin la expansión internacional del capital implicaba la conformación de monopolios asfixiantes de la libre competencia y el predominio parasitario del capital financiero, para Rosa Luxemburgo lo más relevante era la exportación de excedentes invendibles hacia la periferia por parte de los países centrales, como reacción a un agravamiento del sub-consumo. Consideraba que el agotamiento de estos mercados exteriores compensatorios conducía a un punto de estallido definitorio de las crisis de realización.

Por su parte, para Bujarin un nuevo tipo de contradicción se inauguraba en el capitalismo a partir del choque entre la internacionalización económica creciente y el mantenimiento de las formas nacionales de apropiación de los beneficios. Destacaba que los mismos grupos monopólicos que mundializaban sus circuitos de abastecimiento,

${ }^{2}$ Katz, Claudio. El Manifiesto y la mundialización en http:// usuarios.lycos.es/Alfagua/KATZ.html 
producción y comercialización tendían a cohesionarse en torno a estados cada vez más proteccionistas. Estimaba que este proceso potenciaba, simultánea y contradictoriamente, tanto la "universalización" como la "nacionalización" del capital.

Trotsky a su vez, en un primer análisis, destacó que la principal consecuencia de la conformación de un mercado mundial unificado era el ensanchamiento de la brecha entre los países avanzados y atrasados. Planteó que esta polarización reducía drásticamente las posibilidades históricas de las naciones periféricas de repetir el acelerado desarrollo industrial de las potencias centrales. De la constitución definitiva de un sistema capitalista mundial, Trotsky dedujo posteriormente la imposibilidad de aislar el desarrollo económico-social de una revolución triunfante del cuadro internacional y por eso consideró utópico el intento de "construir el socialismo en un solo país". Entendió que la nueva etapa imperialista exigía replantear la estrategia y el proyecto del socialismo a escala mundial.

Estos cuatro interpretaciones representan las bases teóricas para un estudio de la mundialización, porque caracterizan desde distintos ángulos, cuáles son las transformaciones que introduce la penetración del capital en todos los rincones del planeta. Pero para valorar adecuadamente estos aportes hay que separar los elementos coyunturales de sus componentes esenciales, que aparecen entremezclados en los diversos textos. El señalamiento de un salto desde la libre competencia hacia la rivalidad inter-monopólica es un rasgo más perdurable del planteo de Lenin, que el sometimiento del capital industrial al financiero. La creciente necesidad de mercados por parte de las potencias imperialistas y la recurrente opresión de las naciones atrasadas es un aspecto más valioso del análisis de Luxemburgo, que su visión de las crisis exclusivamente derivada del "agotamiento de las regiones no capitalistas".

La contradicción entre la internacionalización de las fuerzas productivas y el mantenimiento de las fronteras nacionales constituye efectivamente el eje explicativo de los grandes conflictos económicos y militares mundiales. Pero las formas de este choque han cambiado sustancialmente desde su caracterización inicial por parte de Bujarin. También ha sido perdurable la visión de Trotsky sobre la creciente polarización entre las naciones opresoras y oprimidas, así como su enfoque de la inviabilidad de todo proyecto socialista exclusivamente concebido en términos nacionales. Pero este proceso no implica un estancamiento prolongado de las fuerzas productivas, como se suponía en los años 30 , sino todo lo contrario. Lo que se ha potenciado es la dificultad creciente para conciliar el aumento de la producción y de la productividad con el ensanchamiento de los mercados y el mejoramiento de las ganancias. Al depurar los rasgos centrales del análisis del imperialismo de las modalidades que adoptó en el período de entre-guerras (1920-1940) se obtiene el núcleo teórico esencial que permi- 
te avanzar en la interpretación actual de la mundialización."

Una segunda acepción del concepto de "mundialización es la definida por Delors et alia (1996). Delors utiliza el término de mundialización para referirse a la interdependencia planetaria en lo económico, científico, cultural y político. Por su parte, Virilio (1997a) nos dice que la mundialización "es el principio del fin del espacio de un pequeño planeta en suspensión en el éter electrónico de nuestros medios de comunicación modernos" (p. 17).

Mària i Serrano (2001a) define a su vez la mundialización como:

“... el proceso por el cual los ciudadanos del mundo comparten una determinada experiencia, un determinado valor o un determinado bien. Pero, como hemos visto, la globalización no ha llegado a todos los ciudadanos del mundo. Existen áreas geográficas o grupos sociales que han sufrido pasivamente la globalización porque han quedado desconectados de las redes de comunicación, de los movimientos de capital, de los destinos de las inversiones empresariales, o de las reivindicaciones de los derechos humanos. Son áreas geográficas o grupos humanos que están al margen de la luz (agujeros negros del capitalismo) y del movimiento que inyecta la globalización allá por donde pasa. La globalización, pues, tal como se ha concretado hasta el momento, no ha repartido sus beneficios a todo el mundo: se queda corta respecto de lo que podría ser la mundialización."

Una visión notablemente más crítica respecto a la mundialización y a las concepciones que la sustentan es la que nos presenta Zaoual (2001)

“La mundialización ha llegado a ser una "máquina incontrolable y excluyente" en la medida en que ella es gobernada por mecanismos económicos culturalmente anónimos. Cada cual sabe que la economía es amnésica. Ella está en las antípodas de la memoria histórica y de la ecología. Para instituirse como ciencia y práctica, ella se ha emancipado totalmente de la ética y de las culturas. Este proyecto de exterminación de la diversidad cultural está en el corazón de sus postulados fundadores. Inspirándose a ultranza en el darwinismo, a pesar de los descubrimientos recientes en la biología sobre el carácter cooperativo de las especies animales y vegetales, la economía permanece atada a la concurrencia vital entre los hombres, las organizaciones y las naciones. El derrumbe de los sistemas inspirados en el marxismo no ha hecho más que amplificar la idea de un modelo único a escala planetaria."

\section{La internacionalización}

Un cuarto concepto asociado a la globalización es el que se ha denominado como la internacionalización, en algunos casos se hace referencia con este concepto a la inter- 
nacionalización de las economías y en otros a la relación entre los Estados-Nación.

"La internacionalización de las economías comenzó verdaderamente en los años sesenta y setenta. Consistió en un simple proceso de apertura de las economías, con las posibilidades y peligros que ello ha creado. Las oportunidades residen en el crecimiento; los peligros en la dependencia, la vulnerabilidad y la segmentación de la sociedad." (Rosanvallon, 2003)

El mismo Rosanvallon busca diferenciar esta noción de la de globalización:

"La globalización por el contrario, no es sólo la internacionalización de los mercados. Es, en efecto, primero y ante todo, la consecuencia de la transformación de los modos de producción, ligada a la tercera revolución industrial de las informaciones y la informática. La globalización no es por tanto una estrategia, una elección de política económica, como podría serlo la internacionalización en los años setenta. Es un elemento intrínseco de la economía moderna."

Josep F. Mària i Serrano (2001a) hace por su parte una referencia a la dimensión más propiamente política de la "internacionalización."

“Internacionalización es el proceso por el cual diversos Estados-Nación se relacionan entre ellos. En este sentido, la globalización exige una internacionalización más intensa porque los Estados-Nación tendrían que apoyarse más entre sí frente a ciertos agentes globales nocivos. Pero, como hemos visto, también se han establecido relaciones entre personas y organizaciones de diversos países al margen de los Estados-Nación: por ejemplo, en las empresas multinacionales, en las ONGs de ámbito mundial, en las redes de economía ilegal, en las visitas de los usuarios de Internet de diversos países a una Web determinada, o en la visión vía satélite de un programa televisivo norteamericano desde países alejados de los EE.UU.. La globalización, por tanto, va más allá de la internacionalización."

\section{La occidentalización}

Hay un quinto concepto vinculado al de globalización, que de un modo análogo al uso del concepto anterior, aunque en un sentido inverso, acuñaron en su uso, Franz Hinkelammert así como muchos de sus seguidores, es el concepto de "occidentalización", que busca dar cuenta de las dimensiones autodestructivas y suicidas de la globalización, tal como es impulsada en la actualidad desde las concepciones neoliberales. Sostiene Hinkelammert (1989) que:

"La sociedad occidental ha producido sistemas de dominación tan extremos, que no tienen antecedentes en ningún período histórico anterior ni en ninguna otra parte del mundo. Sistemas de exterminio de poblaciones enteras. La sociedad occidental ha inven- 
tado también los hoyos negros de los servicios secretos, donde el hombre es deshumanizado hasta niveles insuperables. En todas partes, en todas las líneas ideológicas que han aparecido en esta sociedad, se han dado las peores formas de deshumanización.

La sociedad occidental ha desarrollado fuerzas productivas nunca antes vistas. Pero las ha desarrollado con tanta destructividad, que ella misma se encuentra en el límite de su propia existencia y de la posibilidad de existencia del propio sujeto humano... El siglo XX es sociedad occidental in extremis... La sociedad occidental ha llegado a su fin. Lo que no se sabe es si logrará llevar a la humanidad y a la tierra a este gran hoyo negro que se está creando. Hay una crisis de la sociedad occidental misma en todas sus dimensiones." (p. 9)

"Desoccidentalizar el mundo, eso es esta tarea. Desoccidentalizar la iglesia, desoccidentalizar el socialismo, desoccidentalizar la peor forma de Occidente, que es el capitalismo, desoccidentalizar la misma democracia. Pero eso implica reconocer que el mundo es el mundo de la vida humana en la cual todos tienen que poder vivir. Este reconocimiento constituye la superación de Occidente." (p.12)

\section{La planetización}

Un sexto concepto relacionado al de globalización, es de varios otros autores, que inspirados en la obra de Edgar Morin hacen uso del concepto de "planetización", intentando dar cuenta con éste de la crítica a los grandes problemas de nuestro tiempo, en especial el incumplimiento de la promesa de bienestar y los malestares generados por la civilización occidental tales como: el individualismo como cara perversa del proceso de individuación que ha supuesto la cultura de Occidente; la invasión del cotidiano por la tecnificación; el Estado transformado en el "ogro filantrópico"; la monetarización y la creación de un mercado mundial de bienes y capital que ha ampliado las posibilidades de acceso a productos y servicios del cual vastas mayorías están excluidas.

Según señala Raúl Motta, “la globalización es una totalidad cerrada que deja una diversidad de mundos en la intemperie, es una exclusión, una totalidad imperfecta, como toda totalidad". ${ }^{3}$

Por su parte De Kerckhove (1999a) nos dice que el concepto de planetización difiere del de globalización, ya que mientras que éste se refiere al "proceso de expansión tecnológica y económica de aquí y allí ...", la planetización "es la visión desde arriba, desde el satélite..., es la integración consciente de la realidad dimensional de la Tierra." (p. 212 )

Se resume con este concepto, una crítica a la globalización dominante por su condición de excluyente, simplificadora y reduccionista.

${ }^{3}$ "El pilotaje de la complejidad, las redes sociales y la gobernabilidad planetaria" En Complejidad n² 2, junio- agosto 1996. 
Por ejemplo, hoy se nos busca hacer creer al conjunto de la humanidad que los intereses de Estados Unidos, o más específicamente del sector petrolero de Estados Unidos son los intereses de todos, y hay una cruzada mundial a la que todos debemos adscribirnos. Por el contrario, la planetización, que es sustentada por autores desde el enfoque de la complejidad, supone una nueva conciencia de la co-responsabilidad planetaria, y una nueva actitud frente a los problemas contemporáneos. La conciencia planetaria debe asumir una serie de contradicciones, lo que exige gran apertura y una nueva sensibilidad.

\section{La glocalización}

El séptimo concepto, es el de "glocalización", que es una palabra híbrida creada para unir las nociones de globalización y localización, y que a la vez pretende dar cuenta del carácter contradictorio del fenómeno de la globalización. Con este concepto se intenta entender el actual proceso de transformación como un engarce entre la dinámica local y global, donde lo local gana en significado porque debe participar en un sin número de lugares en la competencia global por los recursos.

Como quiera que definamos el fenómeno de la globalización, los medios de comunicación juegan un importante papel en él. Pero al mismo tiempo los medios de comunicación desempeñan roles contradictorios: pueden ser fuentes de resistencia contra la globa- lización, pero también ser protectores del capitalismo; pueden ser agentes de democratización y herramientas para la glocalización, es decir, constituyen herramientas del doble proceso de globalización de lo local y de localización de lo global que se está dando a nivel mundial y que se define con el término glocalización.

Manuel Castells (1997) hace referencia al concepto glocalización, entendido como la articulación entre lo global y lo local desde una visión urbana, como una noción que hoy se aplica tanto a la economía (la ciudad como medio económico adecuado para la optimización de sinergias) como a la cultura (las identidades locales y su relación dialéctica con el universalismo informacional de base mediática). La glocalización supone para Castells destacar el ámbito urbano y el papel gestor-coordinador-promotor de los gobiernos locales para la implementación de políticas que tienen en cuenta unos referentes globales y que se posicionan respecto a ellos. En síntesis: globalización más proximidad.

\section{Elementos para una definición del concep- to de globalización}

Josep Mária i Serrano (2001b) postula una definición que tomaremos como punto de partida para nuestro análisis:

“...entendemos la globalización como un proceso de interconexión financiera, económica, social, política y cultural acelerado 
últimamente en un contexto de crisis económicas $(1973,1979 \ldots)$, de victoria política del capitalismo frente al socialismo (1989) y de relativización cultural de los grandes ideales (posmodernidad...). Dicha interconexión ha sido posibilitada:

Materialmente, por el desarrollo de las Tecnologías de la Información y la Comunicación (TIC) y el abaratamiento de los transportes; Simbólicamente, por la hegemonía del inglés como lengua de comunicación; y Jurídicamente, por la inexistencia de barreras legales/políticas a la circulación de ideas, dinero, bienes y personas."

Jorge Machado ${ }^{4}$ señala que según Kacowicz (1999), las posibles definiciones del concepto de globalización, deberían incluir:

“... a) la intensificación de las relaciones económicas, políticas, sociales y culturales a través de las fronteras; b) el período histórico iniciado tras el fin de la Guerra Fría; c) la transformación del mundo por la anarquía de los mercados financieros; d) el triunfo de los valores norteamericanos a través de la agenda combinada del neoliberalismo en la economía y la democracia política; e) la ideología y la ortodoxia sobre la culminación lógica e inevitable de las poderosas tendencias de cambio en el mercado laboral; f) la revolución tecnológica con sus implicaciones sociales y g) la inhabilidad de los países en lidiar con

\footnotetext{
${ }^{4}$ www.forum-global.de/soc/bibliot/ machado/conceptglob.htm
}

problemas que requieren soluciones globales como el crecimiento demográfico, los problemas ambientales, los derechos humanos y la proliferación nuclear." (p. 529)

Otros autores hacen referencia a características del proceso global tales como: la agonía de la distancia, la aceleración del tiempo, la desaparición de los intermediarios inútiles, los cambios en el sistema piramidal de transmisión de inteligencia en las organizaciones y/o una nueva forma de hacer economía.

Milton Santos (2002) en su análisis de la globalización, habla de la unicidad de la técnica, la convergencia de los momentos, la cognoscibilidad del planeta y la existencia de un motor único de la historia representado por la plusvalía globalizada.

"La unicidad de la técnica hace posible que las diversas técnicas existentes pasen a comunicarse entre ellas, la técnica de la información asegura ese comercio, que antes no era posible. Por otro lado, ella tiene un papel determinante sobre el uso del tiempo, permitiendo, en todos los lugares, la convergencia de los momentos, asegurando la simultaneidad de las acciones y, por lo tanto, acelerando el proceso histórico." (p. 25)

"Nunca hubo antes esa posibilidad - ofrecida por la técnica a nuestra generación - de tener en las manos el conocimiento instantáneo del acontecer de otro. Esa es la gran novedad, lo que estamos llamando unicidad del tiempo o convergencia de los momentos." (p. 28) 
Sontagg y Arenas señalan por su parte que:

"Se trata de una transformación profunda y estructural que altera, al parecer sustancialmente, la dinámica del sistema históricosocial vigente. La globalización, como se ha llamado este fenómeno, va más allá y es diferente de la tendencia que hemos conocido hasta ahora como mundialización de los mercados e internacionalización y transnacionalización del capital. En efecto, estos últimos procesos se basaban primero (especialmente en los siglos XVIII y XIX) en la expansión de la mercantilización de todas las relaciones sociales por el mundo entero y después (particularmente durante la superación de la Gran Crisis en los tiempos de la Segunda Posguerra) en la existencia de varias empresas multinacionales que actuaban como casas matrices desde los centros desarrollados y un gran número de subsidiarias que producían para diferentes mercados locales, a partir de decisiones tomadas en las primeras (justo como Marx y Engels lo habian presagiado). En la economía globalizada se diluye el concepto de centro-satélite a nivel de las empresas y el diseño de los bienes a producir se hace en cualquiera de las unidades y se produce donde quiera que lo señale la economía de fabricación (Drucker, 1989, 118). Esto significa la sustitución de una economía verticalizada por una horizontalizada a escala global."

\section{Las dimensiones de la globalización}

El fenómeno de la globalización, dado su carácter sistémico, incluye un conjunto de niveles o dimensiones a las cuales es necesario hacer referencia. Siguiendo a Mária i Serrano (2001a) distinguiremos los siguientes:

a) El nivel tecnoeconómico está relacionado con las necesidades de supervivencia de los individuos y contempla el surgimiento de tecnologías y su utilización en los procesos económicos de producción y distribución.

b) El nivel sociopolítico está relacionado con las necesidades humanas de convivencia y se centra en los grupos sociales y en las formas de poder político.

c) Por último, el nivel cultural tiene relación con la necesidad de sentido para la persona, e incluye las ideas y los valores de los grupos humanos, traducidos en instituciones que ordenan las vidas de las personas.

Incluiremos además un cuarto nivel, al que llamaremos el nivel ambiental que tiene relación con el entorno o ambiente biofísico tanto natural como artificial en el cual se lleva a cabo la existencia humana.

Cada uno de estos niveles de análisis posee una dinámica propia, marcada por la lógica de funcionamiento de las instituciones que operan en él. El fenómeno de la globalización se manifiesta en el plano económico en el operar de las empresas, de los mercados, del sistema financiero, así como de los trabajado- 
res; en el ámbito sociopolítico en las actuaciones de los movimientos sociales, los partidos políticos o el Estado; en el plano cultural en las conductas que configuran las familias, las instituciones educativas o las instituciones dedicadas al ocio, la entretención y las necesidades espirituales; en el plano ambiental en los impactos que sobre la naturaleza y el ambiente artificial lleva a cabo el funcionamiento de las sociedades humanas.

Por otra parte, todos estos niveles están relacionados e interactúan en todos los sentidos: las acciones empresariales tienen consecuencias ambientales; las culturas locales condicionan las acciones empresariales, las trasformaciones ambientales generan preocupación política, las decisiones políticas condicionan las acciones empresariales, etc. Sin embargo no es posible atribuir a priori a ningunos de estos niveles la preponderancia en la explicación de las diversas realidades sociales.

\section{Globalización tecnoeconómica}

La globalización está estrechamente vinculada al desarrollo de las nuevas tecnologías. Anteriormente señalamos que la globalización era un conjunto de procesos de índole política y económica que conectaban todo el mundo y en este sentido, no podemos dejar de lado la Información y el Conocimiento, factores claves de los cambios experimentados en las cuatro últimas décadas. En el análisis que Giddens (1999) realiza de la globalización como pilar de la Tercera Vía se indica que en el proceso globalizador no hay que perder de vista la revolución de las comunicaciones y la extensión de la tecnología informática ya que la globalización supone también la transformación del espacio y del tiempo en nuestras vidas.

Estas transformaciones se apoyan en una aceleración sin precedentes de los procesos tecnológicos, tanto en lo que atañe al ritmo mismo de las innovaciones como en lo que se refiere al lapso que transcurre entre la innovación y su incorporación en la producción. Tal proceso se inició en los años setenta y ha llegado a ser tildado como la "tercera revolución tecnológica e industrial». Se ha asentado en la electrónica, la informática, la robótica, los nuevos materiales, la genética y la biotecnología.

Las redes telemáticas ocupan un lugar relevante en esta relación que estudiamos, para De Kerckhove (1999a) las redes y la conectividad, entendida ésta como la tendencia a juntar entidades separadas y $\sin$ conexiones previas mediante un vínculo o una relación, son concebidas como nuevas metáforas tecnológicas que afectan a la percepción espacial y temporal, y por tanto rompen con las barreras locales, expandiendo el tamaño de las representaciones mentales del espacio específico en el que nos encontramos.

La introducción en forma acelerada a partir de los años 70 desató una profunda transformación en las formas de producción y de vida 
de mucha gente, sobre todo en los países industrializados y agudizó la competencia entre las empresas. Las menos eficientes desaparecieron y las supervivientes modificaron las técnicas organizativas e incorporaron las TIC para ser competitivas en los ámbitos nacional e internacional. El abaratamiento de los costos del transporte posibilitó, asimismo, a más empresas, la internacionalización de sus actividades.

Todo ello condujo paralelamente a muchos otros cambios producidos en ámbitos concretos de la economía, tales como el desarrollo de nuevas formas de producción. Estas nuevas formas de producción consisten en la desmaterialización de los productos que significa que su valor agregado ha pasado a depender más de los elementos inmateriales que llevan incorporados (diseño, marca, patentes, publicidad, etc.) que de la manipulación física de los elementos materiales que los integran. Lo anterior ha llevado también a desmaterializar las empresas, estas ya no son más un galpón industrial lleno de máquinas y trabajadores y mucho dinero para financiarlo, sino más bien una idea de producto, un aparataje para fabricarlo y un sistema de ventas. Asimismo esto ha abaratado la fabricación de muchos productos, pero del mismo modo ha generado nuevas dinámicas, entre otras: el outsourcing o subcontratación; la venta de la marca mediante franquicias, etc.

Paralelamente se constata una desnacionalización cada vez mayor de los productos.
Esto significa dos cosas: que cada vez consumimos más productos extranjeros; pero también que cada vez más esos productos ya no son hechos en un lugar único, puesto que las empresas que producen bienes intensivos en trabajo no cualificado, trasladan a los países con mano de obra barata las fases del proceso que implican más intensidad de trabajo. Este es el caso de las maquilas, zonas libres de aranceles en las que los empresarios conectados internacionalmente hacen trabajar duramente a la población local para que realice las fases intensivas en trabajo del proceso de producción de determinadas manufacturas. La extensión de esta desnacionalización de los productos es difícil de establecer, pero va en aumento.

Se produce a la vez una globalización en el mundo del trabajo cuyos resultados son la división digital (aquellos que son capaces de manejar las TIC y adaptarse a los cambios que éstas imponen y los que no, una cronificación dei desempleo, el aumento de la precariedad laboral y social en los países industrializados y también en los en vías de desarrollo, un debilitamiento de la capacidad negociadora de los trabajadores, así como un incremento de la desigualdad de ingresos.

Asimismo se llevan a cabo cambios en el mundo del capital, los que se concretan en un desplazamiento del poder económico hacia los "nuevos ricos"; la desconexión de los mercados financieros respecto de la economía real; la tendencia a la concentración empresarial; una acentuación de la 
competencia y el alejamiento y la progresiva anonimización del capital.

En este sentido, la integración a escala global de los mercados financieros (facilitada por las TIC) acentúa el anonimato y la deshumanización de las decisiones empresariales. Hoy las bolsas más importantes (Londres, Nueva York, y Tokio) están conectadas las 24 horas del día; y mueven unas cantidades de dinero que ningún gobierno puede controlar. Según Lafontaine y Müller ${ }^{5}$ en 1995, se movieron en el mercado de capitales 1,5 billones de dólares cada día, cuando los pagos del comercio internacional sólo necesitan diariamente 10.000 millones de dólares. De modo que, los capitales corren a una velocidad 150 veces superior a lo que necesita la economía real.

Todo ello en un contexto de creciente pérdida de autoridad económica de los Estados. Si bien hasta ahora la actividad económica estaba "domesticada" por los Estados que imponían las condiciones marco del mercado y velaban por el bienestar general, hoy la economía salta fronteras y los agentes estatales de política económica cuentan cada día con instrumentos más débiles para controlar las variables macroeconómicas básicas, para defender la libre competencia o para redistribuir rentas de los ricos a los pobres. Muchos gobiernos están fomentando la liberalización indiscriminada del comercio y de los movimientos de capital, y al mismo tiempo,

${ }^{5}$ Lafontaine, O. y Müller, Ch. (1998) No hay que tener miedo a la globalización, Biblioteca Nueva, Madrid, p. 35. trabajan por la consolidación de grandes empresas "nacionales" fuertes capaces de competir en el mercado mundial. Esta estrategia de impulso de "multinacionales de base nacional propia", ha tenido no obstante consecuencias nocivas: las grandes empresas (tanto de base "nacional" como "extranjera") consiguen de los gobiernos y de los bancos tratos fiscales, financieros, laborales o ecológicos privilegiados. Son los consumidores, las pequeñas y medianas empresas o los ciudadanos más pobres los que acaban pagando estos privilegios y ven reducidos los programas de lucha contra la pobreza por incapacidad presupuestaria del Estado.

Por otro lado, el poder de regulación económica de los Estados se ha reducido también por causa de los movimientos de capitales. Su liberalización fue una decisión política impulsada internacionalmente por el FMI; pero ahora los Bancos Centrales de los países ya no pueden dominar estos movimientos. Los desajustes que se derivan de ello llevan a distorsiones en el funcionamiento de la economía productiva.

En los países subdesarrollados, esta ola liberalizadora ha sido especialmente cruel. A través del mecanismo de la renegociación de la deuda externa, el FMI y el Banco Mundial han obligado a los gobiernos de muchos países no sólo a poner freno a la inflación y a la deuda pública, sino también a privatizar empresas y liberalizar la entrada de capitales o de empresas multinacionales. El pago de la deuda externa ha desviado recursos que 
tendrian que haberse destinado a reforzar el gasto en educación o en salud; la reducción de la deuda pública ha desembocado en la venta de empresas públicas nacionales a capitales extranjeros y ha acentuado la desprotección de los grupos más necesitados. Y la liberalización de la entrada de capitales o de inversiones extranjeras ha acentuado la inestabilidad monetaria y la dependencia exterior de estas economías.

\section{Globalización Sociopolítica}

La globalización se potenció durante la crisis económica de los años 70, pero estas tendencias económicas se reforzaron con la victoria política del capitalismo, escenificada en 1989 con la caída del muro de Berlín. A esta victoria contribuyeron también factores tecnológicos, económicos y culturales.

Como producto de lo anterior se ha pasado de un contexto mundial de confrontación de dos bloques políticos a la competencia entre tres bloques económicos. La política internacional ya no está encuadrada por la confrontación desde bloques "políticos", sino que enfrenta a tres centros económicos con algunas diferencias políticas y culturales: los EE.UU., la Unión Europea y Japón-SE asiático. Hay una serie de coronas concéntricas de países que pretenden conseguir más prosperidad relacionándose con estos tres centros.

Finalmente quedan áreas al margen de la prosperidad y en el seno de las cuales se desarrollan conflictos graves.
Paralelamente se ha producido una crisis del Estado-Nación moderno, originado por un movimiento en dos direcciones: la regionalización (Unión Europea, NAFTA, Pacto Andino, Mercosur) y la revalorización de las unidades políticas subestatales. Ello porque por un lado, hemos tomado conciencia de que determinados problemas (medioambientales, de mercado, de derechos humanos, de delincuencia organizada) se escapan de la dimensión del Estado-Nación, y por otro lado, porque la necesidad de identidad, de relaciones cercanas y de proximidad de los gobiernos respecto de los problemas ciudadanos intenta satisfacerse a nivel subestatal.

En el mismo sentido, Ulrich Beck (1998) define la época actual como una "segunda modernidad". La primera modernidad se produjo con la consolidación del EstadoNación que configuró fuertemente la sociedad circunscrita en el territorio correspondiente. Era un "Estado-contenedor", porque dentro de sus fronteras, y por contraposición a lo que había más allá de ellas, los diversos aspectos de la vida de los súbditos o ciudadanos quedaban muy definidos: idioma oficial, religión, sistema económico y político, sistema educativo... Con la globalización de las relaciones económicas, políticas y culturales, no obstante, nos hallamos en tránsito hacia la "segunda modernidad" en la que se rompe el contenedor: porque los inmigrantes forman grupos culturales o religiosos homogéneos dentro de los Estados; porque gracias a Internet se constituyen comunidades "virtuales" que unen a los que están lejos y 
separan a los vecinos en el espacio; o porque hay ciudadanos que, por tener una biografía globalizada, sienten que pertenecen a varios países a la vez.

El Estado-Nación está evolucionando hacia formas más flexibles de organización, Estadored como la denomina Manuel Castells, que establecen alianzas variables entre diversos niveles de poder (regional, estatal, subestatal). Pero esta flexibilidad pone en peligro las conquistas del Estado de Bienestar.

Por otra parte las democracias liberales occidentales han sido impuestas en muchos países sin diálogo ni voluntad de adaptación. Este fundamentalismo occidental ha desencadenado fundamentalismos antioccidentales en los países en donde se ha impuesto. Aunque si bien el inicio de un sistema penal internacional está contribuyendo a la protección efectiva de los derechos humanos.

Asimismo las instituciones políticas propias de la modernidad - como lo fueron los sindicatos y los partidos políticos - están en crisis. Han surgido en cambio, nuevos movimientos sociales, a menudo con una fuerte preocupación por los problemas mundiales, pero no siempre con intereses universales.

Se ha ido configurando, por último, una nueva división social entre los grupos que han conseguido dominar las TIC y enriquecerse y los que han quedado excluidos y están empobreciéndose. Los triunfadores tienen niveles de vida mucho más elevados que antes, hacen viajes de turismo o de negocios, hablan inglés, dominan la informática y pueden entender los productos culturales (música, cine...) globales. La otra cara de este proceso es la exclusión. Castells bautiza a las exclusiones a partir de una imagen cósmica: las Ilama agujeros negros del capitalismo informacional. Son áreas geográficas enteras o grupos sociales enteros, dentro de los cuales es imposible estadísticamente escapar al sufrimiento o a la degradación progresiva de la condición humana.

El número de gente que cae (o está en riesgo de caer) en estos agujeros negros es cada vez mayor. Una escapatoria posible a esta situación vital es la participación en redes de actividades ilegales: redes de tráfico de drogas, de armas, de niños y mujeres, de inmigrantes ilegales, de tráfico intercontinental de residuos tóxicos. Se busca el triunfo y la riqueza al margen del respeto a la legalidad y a los derechos humanos más básicos.

Los agujeros negros tienen una fuerza de atracción importante, precisamente porque van cayendo en ellos todos aquellos que, por diversas circunstancias, han visto truncadas sus seguridades económicas, sociales y culturales. Y una vez se ha entrado en un agujero negro, es difícil salir de él, porque en su seno actúa una potente y tenebrosa conexión interna: la que en los países ricos, por ejemplo, liga pobreza con malos hábitos alimentarios o de conducta, malos hábitos con fracaso escolar, fracaso escolar con des- 
empleo, desempleo con adicciones, adicciones con prostitución y delincuencia, prostitución y delincuencia con prisiones, prisiones con SIDA y SIDA con muerte.

\section{Globalización Cultural}

La interconexión y la facilidad del transporte que constituyen la base de la globalización han permitido que las personas reciban inputs culturales con tres características nuevas. En primer lugar, estos inputs son mediados por la televisión o por Internet. En segundo lugar, la mayoría de estos inputs culturales globales son productos culturales: han sido elaborados por empresas que esperar sacar beneficios de su venta. Y en tercer lugar, proceden de personas o culturas lejanas, o de una supuesta cultura global reforzada en los últimos años.

Mediante la irrupción de la televisión y del Internet, proveyendo de inputs virtuales en un momento de crisis de los grandes ideales, se ha provocado al mismo tiempo un aumento de las ofertas de tiempo libre y tal vez el fortalecimiento del relativismo y la pasividad. Las relaciones humanas virtuales han ganado importancia e inducen a veces a la confusión entre realidad y ficción.

Se ha instalado, por otra parte una cultura del consumismo global que provoca profundos cambios de valores e incluso comportamientos adictivos. Los productos de la industria de la diversión transmiten valores dema- siado simples, de acuerdo con las exigencias de los productos destinados a las masas.

La cultura del consumismo global tiene que aterrizar en los diversos países, provocando una cierta diferenciación. Pero es discutible si esta diferenciación es realmente sustancial o si finalmente los productos globales constituyen una cultura de la in-diferencia. En todo caso, es necesaria una adaptación activa de estos productos que los convierta en factores de humanización para las personas y los grupos humanos que los reciben.

Los inputs virtuales han inaugurado una nueva modalidad de relación humana: la relación virtual. En ella, nos relacionamos con personas que no tenemos delante físicamente, o con personajes de películas con los cuales no hablaremos nunca, pero que nos transmiten patrones de conducta y orientaciones prácticas. La relación virtual genera lo que Manuel Castells denomina la cultura de la virtualidad real. Es cultura de la virtualidad porque los inputs culturales que se reciben llegan por vía informática, vía juegos de ordenador, vía TV o cine. Es real porque influye realmente en la cultura (ideas, valores y actuaciones concretas) de aquellos que acceden a ella.

De hecho, la frontera entre lo que es real y lo que es virtual llega a desdibujarse en este tipo de cultura: el incesante bombardeo televisivo sobre las mentes y la cantidad cada vez mayor de horas que pasamos delante de la TV Ilevan a la confusión entre ficción y 
realidad. Así pues, si las imágenes de un drama real van seguidas de las de una película, de hecho las primeras pueden ser finalmente "registradas" como medio irreales $y$ las segundas como medio reales.

\section{Globalización ambiental}

Como producto de las dinámicas antes señaladas se constata un creciente deterioro del medio ambiente. Ello porque los diversos agentes económicos han tenido poco en cuenta las consecuencias ecológicas de la producción y el consumo. Así pues, se está produciendo un grave deterioro del medio ambiente, tanto en la tierra como en el mar, como en el aire.

En particular, el incremento del comercio internacional y de la división internacional de los procesos productivos ha sido, al mismo tiempo, causa y efecto del aumento de los transportes. En el medio siglo después de Bretton Woods, se ha producido un alza de alrededor de veinte veces en la actividad global de transportes

Jerry Mander (2002) señala que:

“El Instituto Wuppertal de Alemania realizó un famoso estudio sobre las millas que viaja el alimento desde su punto de origen hasta servirse en el plato. Informa, por ejemplo, que los componentes promedio de un yogurt de fresa de 150 gramos consumido en Europa viajan cerca de 2.000 kilómetros antes de que sean combinados y luego embarcados con destino a los consumidores: las fresas vienen de Polonia; la harina de maíz y de trigo de Holanda; la mermelada, la remolacha azucarera y el propio yogurt de Alemania; y los envases de plástico y de papel de varios otros lugares. Se estima que, en estos días, los ingredientes de un plato de comida tipo que se sirve en las mesas americanas viajan, en promedio,1.500 millas desde su fuente de origen al plato. Cada milla de una actividad tan aumentada de transporte de esta economía global tiene enormes costos para el medio ambiente, costos que se ven externalizados en nuestras actuales medidas de eficiencia, es decir, costos que eventualmente son subsidiados por los que pagan los impuestos."

Actualmente, muchos estiman que el aumento del transporte global es una de las mayores contribuciones a la creciente crisis del cambio de clima y al deterioro del ambiente.

Al respecto, Mander afirma que:

“El transporte marítimo acarrea casi el $80 \%$ de las mercaderías del comercio internacional. El combustible que se usa comúnmente es una mezcla de diesel y petróleo de baja calidad conocido como "Bunker C" que es especialmente contaminante y de muy alto contenido de carbono y azufre. Si no fuera consumido por los barcos se consideraría un producto de desecho. La industria naviera anticipa un mayor consumo para los próximos años: sólo el puerto de Los Ángeles 
proyecta un aumento de 50 por ciento durante la próxima década.

El aumento del transporte aéreo es aún peor que el naviero. Cada tonelada de carga aérea utiliza cuarenta y nueve veces más energía por kilómetro que cuando es transportada por barco. Un físico de la Boeing equiparaba la contaminación debida al despegue de un solo 747 a "incendiar la estación local de gasolina y hacerla volar sobre su vecindad." Un despegue de dos minutos de un 747 es igual a 2.4 millones de cortadoras de césped que funcionaran durante veinte minutos."

Por otra parte se experimenta un exponencial incremento de la pérdida de biodiversidad. Ello porque en los países pobres se transforman zonas selváticas o forestales, en las cuales se tala o se quema el bosque nativo, y los suelos, en la mayoría de los casos muy pobres, se destinan a la expansión de la frontera agrícola, habitualmente a través del desarrollo de economías de colonización o economías campesinas que, al cabo de un corto tiempo, son reemplazadas y destruidas a su vez por la introducción de monocultivos, tales como la caña de azúcar, el café, el banano, u otros, o por la implantación de pastizales para la ganadería o por la plantación de especies forestales exóticas demandadas por la industria maderera. Todo este proceso de civilización y de modernización de la agricultura termina siendo un proceso en el cual, en un período muy corto de tiempo, se ha reducido drásticamente la variedad de especies vivas por hectárea desde cientos de especies a no más de unas decenas.

Mander (2002) sostiene asimismo que:

"Hay otro problema ambiental poco conocido intrínseco a este vuelco hacia el modelo de exportación: la producción monocultural, que provoca enormes problemas ambientales. Por definición, los monocultivos reducen la biodiversidad no sólo por el hecho de eliminar la vida microscópica en los suelos a través del pesado uso de los productos químicos, sino también al reducir la producción de mercaderías a una o dos variedades de exportación. Según la FAO, el mundo ya ha perdido cerca del 75 por ciento de su diversidad de productos agrícolas debido a la globalización de la agricultura industrializada.

Hay que considerar además los costos externos de la agricultura industrial. Reputada como más eficiente que la agricultura a pequeña escala, este tipo de eficiencia ignora sin embargo el costo de la contaminación del aire, del agua, y de los suelos; el creciente uso de combustibles fósiles, pesticidas y herbicidas; la pérdida de humus debido a la producción intensiva con máquinas; y el problema de salud pública que deriva de enfermedades producidas por alimentos directamente relacionados con los sistemas agrícolas fabriles, salmonella, e coli, listeria, y otros. Sin mencionar la enfermedad de las vacas locas, enfermedades como la fiebre aftosa y otras." 
Jeremy Rifkin por su parte afirma que:

"La paradoja del sistema de producción alimentaria actual reside en que millones de consumidores ricos en el primer mundo fallecen por enfermedades relacionadas con la riqueza (enfermedades coronarias, infartos, diabetes y cáncer), provocadas porque se atiborran de ternera y otras carnes ricas en grasa alimentadas a base de cereales, mientras que en el tercer mundo la gente muere de enfermedades provocadas por la pobreza al negársele el acceso a la tierra para cultivar cereales con los que alimentar a sus familias."

El modelo occidental de crecimiento es insustentable. Pero resulta que los medios de comunicación lo están transmitiendo como si no fuera a los países pobres. Y así, muchos ciudadanos de dichos países desean tener los niveles de vida y de consumo que Occidente les muestra en la televisión o en el cine. La extensión de este modelo sería desastrosa para la supervivencia del planeta. Pero asimismo tampoco es sustentable la desigualdad entre ricos y pobres ahora que la televisión la ha puesto en evidencia a los ojos de todos.

\section{Algunos antecedentes para un análisis crítico}

Es frecuente encontrarse con el argumento esgrimido por parte de los partidarios del modelo de acumulación actualmente im- perante en el mundo, de que la globalización se correspondería con una suerte de fenómeno histórico de tipo natural. Una fuerza natural incontrolable. Algo equivalente el estatuto epistemológico que esas mismas personas confieren a las leyes del mercado: iiileyes universales aplicables a los fenómenos económicos en todo momento histórico!!!

Pero en el tratamiento más sistemático, propio de las Ciencias Sociales, se empieza a ver que la Globalización se posiciona como uno de los pilares fundamentales de la transformación económica, política y social. Castells (1997) indica que la Globalización abarca una multitud de manifestaciones (actividad criminal, ciencia y tecnología, medios de comunicación, servicios financieros, profesionales cualificados, arte, turismo, música, cultura, deporte y religión), aspectos éstos que están conectando todo el mundo. Por su parte, Giddens (1999) considera que la globalización puede ser definida como "una compleja serie de procesos, impulsados por una amalgama de factores políticos y económicos" (p. 46), telón de fondo de la política contemporánea y transformadora de las instituciones sociales actuales. Echevarría (1999) a su vez considera que "la globalización no surge de ningún determinismo tecnológico" (p. 98), entendiendo en este marco la globalización como una de las continuas manifestaciones del orden social.

El fenómeno de la globalización tiene lugar debido a la expansión a nivel planetario de la economía occidental. La tesis de Milton 
Santos (2000) es que la globalización es el ápice del proceso de internacionalización del mundo capitalista. Ella ha sido posible gracias al desarrollo de las tecnologías y al estado de la política. Elementos éstos, ambos, profundamente imbricados. A fines del siglo veinte y gracias a los avances de la ciencia, se produjo un sistema tecnológico, presidido por las tecnologías de la información que eslabonaron a las demás tecnologías, uniéndolas y asegurando al nuevo sistema tecnológico una presencia planetaria. Pero también hubo un conjunto de acciones que aseguraron la emergencia de un mercado global. Los factores que explican la arquitectura de la globalización actual son: la unicidad de la técnica, la convergencia de los momentos, la cognoscibilidad del planeta y la existencia de un motor único de la historia representado por la plusvalía globalizada. Un mercado global haciendo uso de los avances técnicos sin control político conduce inevitablemente hacia una globalización destructiva.

Una tesis similar es sostenida por Pat Mooney (2001), quien señala que la tecnología dejada al control de la fuerzas del mercado que apuntan hacia una creciente concentración acentuarán la destrucción de la diversidad cultural y de la biodiversidad.

Muchos otros autores ${ }^{6}$ manifiestan, de manera similar, en diversas publicaciones sus aprensiones y oscuros pronósticos respecto a

${ }^{6}$ Mander, Boff; Hinkelammert, Korten, entre muchos otros. Ver por ejemplo: Varios autores (2002) Globalización y Sustentabilidad: Desafios y Alternativas. Programa Chile Sustentable. Santiago. los negativos resultados de la globalización, de ser ésta dejada al libre manejo de la fuerzas del mercado.

"La globalización moderna no es un accidente de la evolución. Fue creada por seres humanos, y con una meta específica: dar primacía a los valores corporativos por sobre todos los otros valores, e instalar y codificar agresivamente tales valores en forma global.

En el hecho, la era de la globalización moderna tiene una fecha de nacimiento y un lugar de nacimiento: Bretton Woods, New Hampshire, Julio de 1944. Eso ocurrió cuando las figuras corporativas más connotadas del mundo, economistas, políticos y banqueros se reunieron para buscar una forma de mitigar la devastación producida por la Segunda Guerra Mundial. Decidieron que se requería un sistema económico global centralizado para promover el desarrollo económico global. Pensaron que así se dejarían atrás las guerras y se ayudaría a los pobres y al proceso de reconstrucción."

De las reuniones de Bretton Woods surgieron el Banco Mundial, el FMI (Fondo Monetario Internacional) (con otros nombres en esos tiempos) y luego el GATT (Acuerdo General sobre Tarifas y Comercio) que más adelante dio origen a la WTO (Organización Mundial del Comercio); y, en seguida, los clones del modelo incluyeron al NAFTA, el Acuerdo de Maastricht en Europa, la naciente FTAA (Área de Libre Comercio del Acuerdo de las Américas), y varios otros. 
Todos estos instrumentos de globalización económica, en conjunto, han estado cumpliendo con su mandato, que posiblemente traerá consigo el re-planteamiento más fundamental de las disposiciones sociales, económicas y políticas existentes en el planeta, al menos desde los tiempos de la Revolución Industrial. Están implementando un cambio de poderes de enormes proporciones, arrebatando el verdadero poder económico y político a los gobiernos nacionales, estatales y locales y a las comunidades, que conduce hacia un nuevo modelo que da gran poder a las corporaciones globales, los bancos y las burocracias globales que ayudaron a crear, aunque con graves consecuencias para la soberanía nacional, el control comunitario, la democracia, las culturas indígenas y, hoy día sobre todo, para el mundo natural." (Mander, 2002).

Por su parte Boaventura de Souza Santos (2003) sostiene que:

..."aquello que denominamos globalización consiste en múltiples series de relaciones sociales; en tanto estas series de relaciones sociales cambian, la globalización también lo hace. En estricto sentido no existe una entidad singular llamada globalización, sino, en cambio, diversidad de globalizaciones, por lo cual deberíamos utilizar este término únicamente en plural. De otra parte, si las globalizaciones consisten en diversos conjuntos de relaciones sociales, y estas últimas están destinadas a acarrear conflictos, entonces también implican la presencia de ganadores y perdedores. En la mayoría de los casos el discurso de la globalización trata de la historia de los ganadores tal y como es contada por ellos. En efecto, la victoria aparentemente es tan contundente, que los derrotados terminan desapareciendo del todo del panorama." (p. 86)

Otra dimensión, la cual es destacada por Franz Hinkelammert, es la instalación a nivel global de la noción de eficiencia medio-fin:

Cuando hoy hablamos del mundo globalizado, hablamos de este mundo en el cual han aparecido las amenazas globales, a la vez que existe el cálculo medio-fin de parte de empresas de alcance global como un cálculo que se sigue considerando el máximo cálculo eficiente.

Sin embargo, se manifiesta ahora una crisis de la eficiencia que cuestiona todo el sistema. El mundo, como mundo globalizado, está cada vez más amenazado por la misma estrategia de acumulación, que hoy llamamos estrategia de globalización. Precisamente por ser un mundo globalizado, este mundo se encuentra amenazado de manera global por esta estrategia de globlaización que es tan orgullosa de su eficiencia. Eso revela que esta eficiencia es profundamente ineficiente y esta racionalidad profundamente irracional. . (Hinkelammert 1999: 14)

En el análisis que realiza respecto a la dimensión territorial del fenómeno de la globalización Milton Santos introduce la idea de la 
imposición del tiempo dominante, él habla de la existencia de dos circuitos de la economía: uno dominante y otro dominado, siendo el primero el que impone su ritmo y tiempo al otro. De modo tal que es la mayor velocidad de circulación de los diversos flujos (financieros, informacionales, físicos, demográficos) lo que hace que el circuito superior vaya progresivamente destruyendo el tiempo de los otros circuitos e imponiendo el suyo.

La historia es comandada por los grandes actores del tiempo real, que son, al mismo tiempo, los dueños de la velocidad y los autores del discurso ideológico. Los humanos no son igualmente actores de ese tiempo real. Físicamente, esto es potencialmente, él existe para todos. Pero efectivamente, esto es, socialmente, él es excluyente y asegura exclusividades, o, por lo menos, privilegios de uso (Santos 2000: 28)

Ello da origen al inédito fenómeno de la coetaenidad de lo no coetáneo, esto es la coexistencia de personas y sociedades enteras que viven en la premodernidad, mientras que otros viven la modernidad e incluso algunos la posmodernidad, pero afectándose mutuamente sus existencias. La globalización como fenómeno histórico se da en un contexto de enorme asimetría de poder económico y político, de modo tal que contribuye a incrementar exponencialmente esa asimetría a niveles prácticamente inimaginables.

Asimismo la globalización lleva al plano individual elementos hominizadores que son esencialmente colectivos, arriesgando así el propio devenir evolutivo de la especie. Cada ser humano, dado su actual nivel evolutivo, requiere una diversidad de modelos culturales entre los cuales optar, lo contrario podría implicar un riesgo involutivo. Pero del mismo modo la globalización universaliza experiencias humanas que habiendo surgido en espacios y culturas locales terminan siendo impuestas a rajatabla en contextos geográficos y culturales que no les son propicios, generando una falacia de universalización.

Como lo señala Boaventura De Sousa Santos:

"Esta es mi definición de globalización: es el proceso mediante el cual una condición o instancia local logra extender su radio de influencia a lo largo del globo y, al desplegar esta acción, desarrolla la capacidad de designar como local a la instancia o condición social con la cual compite." (2003: 86)

El problema, por consiguiente, es analizar los grados de autonomía posible que pueden tener en un mundo globalizado, aquellos territorios, espacios y seres humanos a quienes la globalización va convirtiendo en población excedentaria, población sobrante, ejército industrial de reserva, marginados, excluidos, condenados de la tierra, desechables, entre otras tantas categorías conceptuales con las cuales se ha buscado llamar en el decurso de las ciencias sociales. ¿Tendrán algún lugar en la historia futura aquellas masas marginales, miserables y hambrientas, construidas gracias al desarrollo del capitalis- 
mo, las cuales pese a todos los sistemáticos esfuerzos por hacerlas desaparecer ya sea integrándolas, funcionalizándolas e incluso exterminándolas, siguen aún porfiadamente existiendo? ¿No son estas ciudadanías desespacializadas uno de los síntomas más profundos de la crisis del sistema democrático y de la civilización occidental?

Hay quienes buscando plantear una alternativa no sólo a la actual globalización, comandada por el neoliberalismo, sino a su dimensión homegenizadora y universalizante, proponen ya sea la idea de la glocalización (Castells) o la de la existencia no de una sino que de varias globalizaciones (De Sousa Santos). La pregunta que subyace sin embargo, es si es posible responder a la globalización perversa como la llamó Milton Santos con una globalización incluyente y solidaria. La que se esboza en la consiga de los Foros Sociales Mundiales de que "Otro mundo es posible".

\section{Bibliografía}

Acosta, Alberto (comp.) (2000) El desarrollo en la globalización. El reto de América Latina.ILDIS/Editorial Nueva Sociedad, Caracas.

Acosta, Alberto (2003) “En la encrucijada de la glocalización. Algunas reflexiones desde el ámbito local, nacional y global" en Polis. Revista de la Universidad Bolivariana. Volumen $1 \mathrm{~N}^{\circ} 4$. Santiago.

Acosta, Yamandú y Rico, Álvaro (comp.) (2000) Filosofía latinoamericana, globalización y democracia, Nordan. Montevideo.

Aguirre, Mariano, Filesi, Teresa y González, Mabel (eds.) (2000) Globalización y sistema internacional. Las claves para entender la realidad mundial. Icaria. Barcelona.

Amin, Samir y Houtart, François (eds.) (2003) Globalización de las resistencias. El estado de las luchas 2003. Icaria/Caritas. Barcelona.

Arrighi, Giovanni (1999) El largo siglo XX. Ediciones Akal S.A. Madrid.

Arrighi, Givanni y Silver Beverly J. (2001) Caos y orden en el sistema-mundo moderno. Ediciones Akal S.A. Madrid.

Balbín, Jesús y Arango, Oscar (2003) Globalización de los Derechos... Repensando la condición humana. Instituto Popular de Capacitación. Medellín. 
Bauman, Zygmunt, La globalización. Consecuencias humanas, Fondo de Cultura Económica de Argentina, Buenos Aires, 1999.

Beck, Ullrich (1998) ¿Qué es la globalización? Paidós, Barcelona..

Borja, Jordi y Castells, Manuel (1997) Local y global. La gestión de las ciudades en la era de la información. Taurus. Madrid.

Brenner, Robert (1999) Turbulencias en la economía mundial. LOM Ediciones, Santiago.

Bujarin, Nicolai (1971) La economía mundial y el imperialismo. Pasado y Presente $N^{\circ} 21$, Buenos Aires, 1971.

Castells, Manuel (1999) La era de la información. Economía, sociedad y cultura, Alianza Editorial, Madrid.

Cortina, Adela (1997) Ciudadanos del Mundo. Hacia una teoría de la ciudadanía.

Editorial Alianza. Madrid.

Chomsky, Noam y Dieterich, Heinz (1996) La sociedad global. Educación, mercado y democracia. LOM Ediciones, Santiago.

Delors, Jacques et alia (1996) La Educación encierra un tesoro., Santillana Ediciones/ UNESCO, Madrid.

De Kerckhove, D. (1999a) Inteligencias en conexión. Hacia una sociedad de la web. Gedisa, Barcelona.
De Sousa Santos, Boaventura (2003) La caída del Angelus Novus. Ensayos para una nueva teoría social y una nueva práctica política. ILSA. Bogotá.

Dieterich, Heinz (edit.) (1999) Fin del Capitalismo Global. El Nuevo Proyecto Histórico. Editorial Ciencias Sociales, La Habana.

Echevarría, Javier (1999). Los señores del aire: Telépolis y el Tercer Entorno. Destino. Barcelona

Estefanía, Joaquín (2002) “Globalización” en Conill, Jesús (coord.) Glosario para una sociedad intercultural.

Bancaja, Valencia.

Giddens, Anthony (1999). La Tercera vía. Taurus. Madrid.

Heilbronner, Robert (1996) El Capitalismo del Siglo XXI. Penísula. Barcelona.

Hinkelammert, Franz (1989) La fe de Abraham y el Edipo Occidental. Editorial DEI. San José de Costa Rica.

Hinkelammert, Franz (comp.) (1999) El Huracán de la Globalización. Editorial DEI. San José de Costa Rica.

Hinkelammert, Franz (1996) El Mapa del Emperador. Determinismo, Caos, Sujeto. Editorial DEI. San José de Costa Rica. 
Jiménez Herrero, Luis M. (2002) “Globalización económica y ecología global" en Novo, María (edit.).Globalización, crisis ambiental y educación. Ministerio de Educación, Cultura y Deporte. Aulas de Verano. Madrid.

Kacowicz, Arie M. (1999) Regionalization, Globalization and Nationalism: Convergent, Divergent, or Overlaping?, in Alternatives, vol. 24, n. 4, oct-dez, 527-555.

Korten, David C. (1998) Cuando las transnacionales gobiernan el mundo. Cuatro Vientos. Santiago.

Lenin, Vladimir (1973) El imperialismo, fase superior del capitalismo. De Anteo, 1973.

Luxemburgo, Rosa (1968) La acumulación del capital, S/E., Buenos Aires.

Machado, Jorge A. S. (2001), Concepto de Globalización, http://www.forum-global.de/soc/bibliot/ machado/conceptglob.htm

Mander, Jerry (2002) “Globalización y medio ambiente" en Globalización y Sustentabilidad: Desafíos y Alternativas. Programa Chile Sustentable. Santiago.

Mària i Serrano, Josep F. (2001a) Globalisation. Cristianisme i Justícia, Barcelona. Versión castellana en http://www.fespinal.com/espinal/castellano/ visua/es103.htm
Mària i Serrano, Josep F. (2001b) “La globalización" en Las otras caras de la globalización. Documentación Social № 125 , Octubre -Diciembre 2001, Caritas Española, Madrid.

Mayor Zaragosa, Federico (1999) Los nudos gordianos. Galaxia Gutenberg. Barcelona.

McLuhan, Marshall (1954) Understanding Media. Publicada en castellano como Comprender los medios de comunicación (1996), Paidós, Barcelona.

Mc Luhan, Marshall (1962) The Gutemberg Galaxy Publicada en castellano como La galaxia Gutenberg (1993), Círculo de Lectores. Barcelona.

Monsalve, Alfonso (1998) Estado, sociedad internacional y derechos humanos en un mundo globalizado. Un estudio desde la ética argumentativa. Editorial Universitaria de Antioquía. Medellín.

Mooney, Pat Roy (2002) El Siglo ETC. Erosión, Transformación Tecnológica y Concentración Corporativa en el Siglo 21. Nordan. Montevideo.

Naredo, José Manuel (2003) “Claves de la globalización financiera y de la presente crisis internacional" en Polis. Revista de la Universidad Bolivariana. Volumen $1 \mathrm{~N}^{\circ} 4$. Santiago. 
Novo María (2002) “Globalización, cambio de paradigma y educación ambiental" en Novo, María (edit.). Globalización, crisis ambiental y educación. Ministerio de Educación y Deporte. Madrid.

Perlas, Nicanor (1999) Shaping Globalization,. Civil Society, Cultural Power and Threefolding. CADI. Quezon City. Filipinas.

Ramonet Ignacio (2000) "Situación actual del proceso de globalización" en Aranguren, Luis et alia. El proceso de globalización mundial. Hacia la ciudadanía global. Documentos Intermón. Barcelona.

Rifkin; Jeremy (2002) "Ante una auténtica crisis alimentaria global" en El País, lunes 10 de junio, Madrid.

Rosanvallon, Pierre (2000) La globalización exige un nuevo contrato social. PNUD/Gobierno de Chile. Temas de Desarrollo Humano Sustentable № 4 , Santiago.

Santos, Milton (2000) Por uma outra globalização. Do pensamento único à consciencia universal. Editora Record. Segunda edição. Rio de Janeiro.

Sonntag, Heinz y Arenas, Nelly (1995) Lo Global, Lo Local, Lo Hibrido.Aproximaciones a una discusión que comienza. Gestión de las Transformaciones Sociales - MOST. Documentos de debate $\mathrm{N}^{\circ} 6$.

Stiglitz, Joseph (2002) El malestar en la globalización. Santillana, Madrid.
Trotsky Leon (1969) La revolución traicionada, México.

Trotsky Leon (1972) Resultados y perspectivas. De Cepe, Buenos Aires.

Ugarteche, Oscar (1997) El falso dilema. América Latina en la economía global. Editorial Nueva Sociedad. Caracas.

Urriola, Rafael (1996) Economía Latinoamericana. La globalización de los desajustes. Editorial Nueva Sociedad, Caracas.

Varios autores (2002) Globalización y Sustentabilidad: Desafíos y Alternativas. Programa Chile Sustentable. Santiago.

Varios autores (1998) Estado y globalización. ILDIS/Tramasocial Editorial. Quito.

Varios autores (2001) Las otras caras de la globalización. Documentación Social № 125 , Octubre -Diciembre 2001, Caritas Española, Madrid.

Varios autores (2003) Por una nueva globalización. Polis № 4, Universidad Bolivariana, Santiago.

Virilio, P. (1997a). La Bomba Informática, Cátedra, Madrid.

Virilio, P. (1997b). El Cibermundo: la política de lo peor, Cátedra, Madrid. 
Wallerstein, Immanuel (1974) The Modern World-System: Capitalist Agriculture and the Origins of the World-Economy in the Sixteenth Century, vol. 1, Academic Press, New York. (edic. castellana El moderno sistema industrial I. La agricultura capitalista y los orígenes de la economía-mundo europea en el siglo XVI, Siglo XXI de España, Madrid, 1979.

Wallerstein, Immanuel (1980) The Modern World-System: Mercantilism and the Consolidation of the Europena World-Economy, 1600-1750, vol. 2, Academic Press, New York. (edic. castellana El moderno sistema industrial II. El mercantilismo y la consolidación de la economía-mundo europea, 1600-1750, Siglo XXI de España, Madrid, 1984.

Wallerstein, Immanuel (1989) The Modern World-System: The Second Era of Great Expansion of the Capitalist World-Econom. 1730s-1840s, Academic Press, New York. (edic. castellana El moderno sistema industrial III. La segunda era de gran expansión de la economía-mundo capitalista, Siglo XXI de España, Madrid, 1999.

Wallerstein, Immanuel (1997) El futuro de la civilización capitalista. Editorial Icaria. BarceIona.

Zaoual, Hassan (2001) Le mosaïque des cultures face a un monde uniforme. Foi et Devéloppment №290, janvier 2001, Paris. Publicado en castellano en Polis $N^{\circ} 2$ como El mosaico de culturas encara a un mundo uniforme, Universidad Bolivariana, Santiago, 2001. Disponible en Internet en http:// www.revistapolis.cl/2/dos.htm 